\title{
Research on the development strategy of emergency management system of power grid companies
}

\author{
Yan ZHANG ${ }^{1}$, Chen ZHANG ${ }^{1}$, Zhenwei $\mathrm{LI}^{2}$, Xubin WANG ${ }^{1}$, Xin TIAN ${ }^{1}$, Xinyang HAN ${ }^{1}$ \\ ${ }^{1}$ State Grid Energy Research Institute, 102209, Beijing, China \\ ${ }^{2}$ State Grid Xiongan New Area Electric Power Supply Company, 071000, Xiongan, China
}

\begin{abstract}
In recent years, major emergencies show new trends and characteristics. The reform of the national emergency management system has continued to deepen, and the demand for emergency power supply has continued to increase. Thus it is urgent for the power system company to improve the company's emergency management system, the ability to deal with urgent, difficult, and difficult tasks. This article analyzes the situation facing the modernization of the company's emergency system, and puts forward the overall ideas and key measures to support emergency management reform and capacity improvement with the principle of "integration, normalization, socialization". ${ }^{1}$
\end{abstract}

\section{Introduction}

Major emergencies show trends such as frequent, globalization, unconventional, and coupling. The reform of the national emergency management system is continuously deepened[1-3], and the demand for emergency power supply in politics, economy, society, and people's livelihood[4] continues to increase. This article will summarize and sort out the trend characteristics of major emergencies, analyze the current situation of the company's emergency system and capacity building, evaluate the adaptability of the company's emergency system and capabilities under the new situation, propose the company's emergency management system and capacity improvement strategic ideas and key tasks, and consolidate response experience, Improve disposal capacity.

This article intends to solve three key issues:

(1) Situation analysis: clarify the challenges faced by emergency management under the new trend of major emergencies;

(2) Needs assessment: Analyze the development status of the company's emergency response system, and clarify the company's emergency management system and capacity improvement requirements;

(3) Strategy design: In view of the improvement requirements, it is clear what strategies and measures the company should adopt, improve the emergency management system, improve emergency response capabilities, and achieve the matching of emergency response capabilities with goals.

\section{New trends and characteristics in major emergency}

Influenced by changes in the natural environment and development of economic and society, major emergencies present new trends and characteristics, and its prevention, preparedness, response and recovery are challenged on a broader scale.

At present, major emergencies show the following trends[5]: (1) High frequencies caused by increased extreme weather, aging infrastructure, shortened production cycle. (2) Ubiquity resulted by intense risk in urban, low defense in rural, and the supply chain in globalization. (3) Unconventionality since new forms of security risks such as biology and network attacks. (4)Coupling since the correlation of disaster-causing factors and the cross-class spread of emergencies.

The characteristics of major emergencies are as: 1) the high uncertainty of time, place and degree of influence, 2) the cognitive limitations caused by the lack of effective technology and knowledge support, 3) the dynamic complexity caused by multiple disaster-causing factors and variability, 4) the widespread spread caused by the continuous spread of space-time dimensions, and 5) the devastating effects caused by short-term violent shocks and derived continuous effects. 
trends

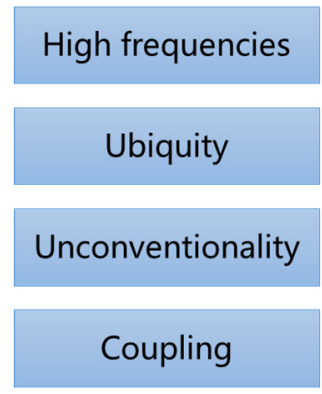

characteristics

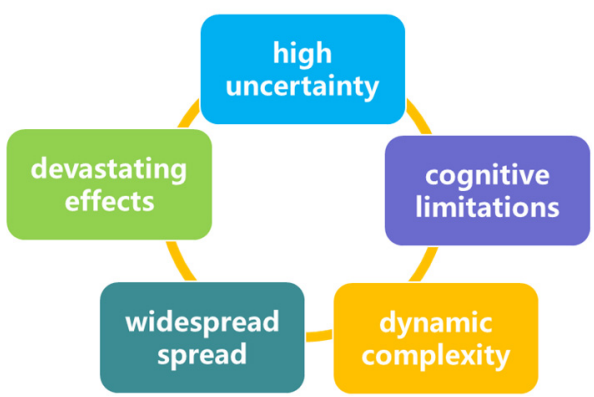

Fig. 1 Trends and characteristics of major emergencies

\section{The foundation of emergency management in SGCC}

The emergency management of the SGCC are coordinated by the Dept. of Safety and Supervision and the General Office, and the specific work involves more than ten departments, such as the Dept. of Development, the Dept. of Equipment, the Dept. of Infrastructure, the Dept. of Materials, the Dept. of Logistics. At present, the company continues to strengthen the emergency management system and capacity-building, forming an industry-wide emergency management structure, covering "four systems, six capabilities."

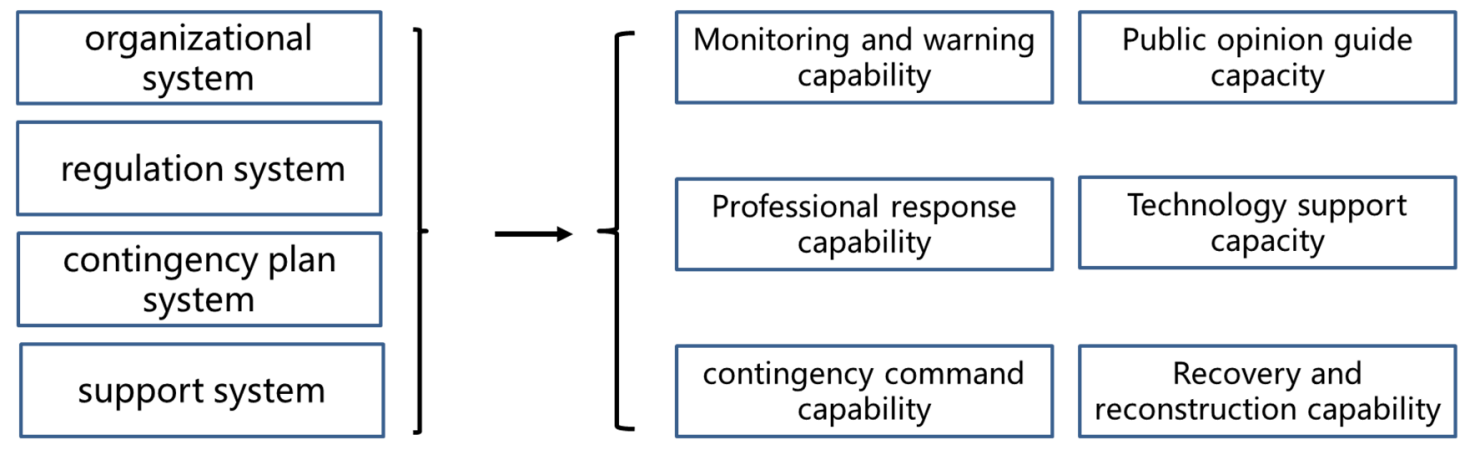

Fig.2 "four systems, six capabilities" of SGCC emergency management system

The framework of emergency management system is well established. In terms of organizational system, emergency command and management agencies covering the headquarters(sub-unit), provinces, municipal and county-level companies have been established; in terms of regulation system, a series of rules, such as emergency management rules and emergency command center management rules, as well as emergency technical standards such as the evaluation norms for emergency capacity-building of power grid enterprises and the guidelines for emergency drills for large-scale power outages, have been formulated and issued; in terms of the emergency plan system, cumulative preparation covers four types of events, emergency plans at all levels and on-site disposal programs of nearly 300,000 items, built two company-level training exercise bases in Shandong and Sichuan, and constantly improved the construction of emergency training subjects, the implementation of the exercise organization.

Emergency ability-building has made steady progress. In terms of monitoring and early warning capacity, a disaster prevention and mitigation center was set up in Hunan Electric Power, an emergency technology center was established at the Global Energy Internet Research Institute, and an early warning system for monitoring natural disasters such as rain and snow freezing, storm geology and forest grassland fires was established; in terms of Professional response capacity, SGCC emergency rescue team, emergency repair team and emergency expert team are set up , professional equipment is configured, emergency communication system, emergency power system, emergency airspace force are built; in terms of comprehensive support, 6 company-level emergency materials depots, 77 provincial-level library, 1737 municipal and sub-level depots are built, through physical reserves, agreement reserves, dynamic turnover and other means to ensure emergency supplies reserves and supplies.

\section{New challenges in the construction of emergency management systems}

State Grid Corporation's emergency management is in the development stage from special emergency response to comprehensive emergency, from empirical emergency to scientific emergency, from passive response to active protection.

Externally, the normalization of the epidemic, compound disasters, unconventional warfare, network 
security and other complex risk factors, the increase of energy market and service market subjects bring new coordination needs, external emergency protection tasks and the negative impact of emergencies intensified, all put forward new and higher requirements for the company's emergency management system and capabilities.

Internally, transforming the emergency management mode, strengthening the government- industry-social participation, promoting the integration of emergency resources within the company, smoothing the emergency management process, integrating the edging technology and theory and strengthening the foundation of emergency hardware and software are the internal driving force for the company to improve the level of emergency management.

There are still some short boards and shortcomings in the company's emergency management.

First, the company's emergency work overall coordination is insufficient. The emergency plann system at or above the provincial level is generally complete, but some city and county companies just copy and is not operational; emergency materials, personnel, equipment coordination and support mechanism is to be perfected, cross-regional personnel and material deployment mechanism is not mature; multi-professional emergency information platform integration is not sufficient

Second, the degree of refinement of emergency management is insufficient, which restricts the normal improvement of coordination, disposal and resource allocation capacity. Some leading cadres have insufficient emergency response capacity, which leads to the deviation and lag of emergency decision-making; the emergency coordination agency is temporary and insufficiently functional, and is difficult to implement integrated coordination and professional disposal responsibilities; the shortage of emergency management personnel and the unbalance of full-time and part-time configuration of emergency response teams limit the ability and response speed; the standardization and differentiation of emergency technical equipment are insufficient, which affects the efficiency of emergency coordination.

Third, there are bottlenecks in emergency protection capacity under extreme scenarios, and the interface with social resources is insufficient. Under extreme scenarios such as war, the key infrastructure and important users of the power grid may become the key targets, the power grid's survivability is insufficient, the coordination mechanism between government and enterprises needs to be established; the cooperation mechanism with meteorological, geological and other external units lacks the top-level cooperation framework, the technology, data and other resources sharing mechanism still needs to be perfected; the cooperation mechanism with socialized emergency resources is not perfect, and the channel of cooperation with external construction forces, logistics services and logistics resources is not stable.

\section{The overall strategy and main tasks of emergency system construction}

Starting from the need to improve the ability to prevent and resolve major emergencies, the future company emergency system must focus on all-round capacity-building, adhere to the basic principles of integration, normalization and socialization.

\section{1 overall strategy}

\section{(1) integration}

1) strengthen basic governance

improve the systematic level of emergency standard regulation, improve the efficiency of the company's comprehensive coordination of emergency response, achieve joint management of the emergency response system,

\section{2) pay attention to risk prevention}

integrate emergency preparedness prevention and risk monitoring and early warning into the company's overall planning, realize emergency strength and resources ahead of the reserve;

\section{3) Strengthen information support}

promote the modernization of emergency management with information technology, improve monitoring and early warning capabilities, assist emergency dynamic decision-making, and empower emergency collaboration networks.

\section{(2) normalization,}

\section{1) Build permanent coordination agency}

improve the authority of comprehensive coordination, reduce the cost of coordination, accelerate the accumulation of experience and system training, ensure operational effectiveness,

\section{2) strengthen professional skills}

improve the emergency watch, monitoring and early warning, rescue and disposal, public opinion guidance, logistics services and other duties division and staffing;

\section{3) Standardize training exercises}

Improve the "emergency response ability" of leading cadres, realize the "self-organized response" of professional teams, and ensure that emergency decision-making and organization implementation do not deviate from the organization.

\section{(3) socialization}

1) sort out external emergency needs

improve the working mechanism of power emergency resources to serve the society and people's livelihood.

\section{2) Actively connect with social resources}

improve the comprehensive protection level of power emergency through co-construction and sharing, service purchase, etc.

\subsection{Main tasks}

(1) Explore the normal operation of emergency coordination agencies and supporting agencies, and optimize the emergency organization system.

The first is to set up permanent rescue and repair, disaster statistics, site management and control, material 
support and information publicity and other functional working groups under the emergency leading groups at all levels. In emergencies, they can be modularized and combined as needed to improve coordination efficiency. The second is the establishment of professional support departments at the headquarters level in directly affiliated units, and the provincial company level adds emergency management centers according to needs, and is usually responsible for emergency support system planning, emergency duty, training exercises, command center operation and maintenance, emergency capability assessment and inspection, etc. Responsible for intelligence collection and circulation, data statistics, affairs coordination, etc.; in the long-term, to meet the needs of national emergency management system and mechanism reforms, and to explore cohesive company emergency management institutions and operating modes.

(2) Optimize the positioning of plans at all levels, coordinate the advancement of scenario-based plan revisions and drills, improve the level of digitalization, and consolidate the emergency plan system.

The first is to clarify the institutional arrangements in the overall plan. At the headquarters level, strengthen the overall planning strategy leading role, formulate complex and secondary-derived catastrophe scenarios, and clarify the emergency linkage mechanism across departments, regions, and governments and society. The second is to formulate special plans for catastrophe scenarios at the provincial company level based on overall plan requirements and regional differences; improve the feedback and improvement mechanism of "drills-plans-system"; promote and improve on-site disposal plans for power supply stations, grassroots teams and emergency response cards for key positions; clarify the list of key tasks and emergency procedures to improve the emergency response capabilities at the grassroots level. The third is to carry out the digital decomposition of the text plan. When an emergency occurs, the emergency response measures will be automatically pushed to the relevant personnel to improve the operability of the plan.

(3) Implement differentiated disaster prevention and mitigation projects to improve source governance capabilities.

The first is to actively carry out the differentiated design of grid protection construction standards. In accordance with the severity of regional disasters, optimize grid construction standards by grading and partitioning, implement disaster-resistant power supply layout, and strive to ensure that there is no power outage and fewer power outages in urban core areas and key users under extreme natural disasters. Taking coastal cities as an example, the construction of "cable lines + indoor sites" disaster prevention and disaster relief "lifeline power grids" can be carried out. The second is to improve the autonomy of local distribution networks. Drawing on the experience of smart grid construction in the United States, Japan, etc., develop new power supply systems such as distributed power sources, microgrids, and energy storage according to local conditions, explore the application of emergency power supply technology for electric vehicle services, and enable key regions, important bases and institutions to have independent power supply capabilities under extreme scenarios

(4) Upgrade the smart emergency command center to improve decision-making and command capabilities.

The first is to coordinate the stock resources with embedded development. The application resources and production operation data of the company's existing dispatching, equipment, marketing, materials, logistics and other departments are called through embedded development to ensure real-time compatibility with the company's existing application systems and assist emergency dynamic decision-making. The second is to strengthen data empowerment and realize the intelligent management and operation of the emergency command center. Make full use of the big data and AI technology to develop rapid acquisition of basic information such as disaster information, power grid status, and resource allocation, intelligent analysis of disaster situations based on artificial intelligence, emergency assistance decision-making based on big data, and visual command based on live video and other functions.

(5) Build a professional emergency team to improve professional handling capabilities.

The first is to optimize the key team configuration mode. Provincial companies adopt part-time or full-time rotation, and city and county companies rely on restructuring teams to build backbone teams to ensure the speed of emergency response. The second is to optimize the efficiency of professional team construction. Relying on the personnel of the provincial power transmission and transformation or maintenance company, build a regional and mobile company-level professional emergency rescue team; broaden the communication channels of personnel skills such as preparation and emergency duty to improve the actual emergency combat capability. The third is to build a special team to improve the ability of special disposal. Relying on the general aviation company to establish an airspace emergency survey and rescue team; relying on the maintenance company to establish a fire emergency response and rescue team; relying on the information and communication company, the joint research institute, and the information industry group to build a network attack emergency support team.

\section{Conclusion}

In this paper, new trends and characteristics in major emergency is analyzed, and current situation of SGCC emergency management system are summarized. Three anapests of shortcomings are identified and the overall strategy of "integration, normalization and socialization" is proposed to tackle it.

This work is supported by Science and Technology Project of SGCC (Research on Design and Control of Power Grid Intrinsic Safety Framework) 


\section{Reference}

1. Chen Zhenming. The rise of emergency management in China: Development of theories and their applications[J]. Southeast Academic Research, 2010, (1): 41-47.

2. National General Emergency Plan for Sudden Public Security Events. People's, http://politics.people.com.cn/GB/14538 /4007544.html, 2006- 01-08.

3. Zhang Liyong. Government's emergency management system and assessment[D]. Hefei: Hefei Industrial University, 2007.

4. Mc Loughlin. A framework for integrated emergency management[J]. Public Administration Review, 1985, 45: $165-172$.

5. An Emergency Management Framework for Canada[R]. Public Safety Canada, 2009. 